\title{
INFORMAÇÃO DE PATENTES: FERRAMENTA INDISPENSÁVEL PARA A PESQUISA E O DESENVOLVIMENTO TECNOLÓGICO
}

\author{
Luciana Goulart de Oliveira* e Raul Suster \\ Centro de Divulgação, Documentação e Informação Tecnológica, Instituto Nacional de Propriedade Industrial, Praça Mauá, 7 , \\ 20081-240 Rio de Janeiro - RJ \\ Angelo C. Pinto \\ Instituto de Química, Universidade Federal do Rio de Janeiro, Cid. Univ. Ilha do Fundão, 21949-900 Rio de Janeiro - RJ \\ Núbia Moura Ribeiro e Rosângela Bezerra da Silva \\ Centro Federal de Educação Tecnológica em Química, Rua Lucio Tavares, 1045, 26530-060 Nilópolis - RJ
}

\begin{abstract}
INFORMATION ON PATENTS: AN INDISPENSABLE TOOL FOR RESEARCH AND TECHNOLOGICAL DEVELOPMENT. As technological information is published mainly as a patent, it is fundamental for the country development to know the patent system. In this article it is presented basic information on intellectual property, in special on patent. It is showed the structure of the patent documents, and it is given notions on International Classification and patent data banks.
\end{abstract}

Keywords: patent; intellectual property; patent databanks.

\section{INTRODUÇÃO À PROPRIEDADE INTELECTUAL}

A partir da Revolução Industrial, a aplicação bem-sucedida de conhecimentos científicos para produção de tecnologias passou a ocorrer em larga escala. Desde então o conhecimento científico deixou de ser um bem permanente cultural e tornou-se um insumo para o sucesso econômico. Surgiu então o conceito de "propriedade intelectual".

Estima-se que desde a Revolução Industrial, os conhecimentos científicos e tecnológicos têm duplicado a cada 10 a 15 anos, e mais de $80 \%$ deles foram gerados após a Segunda Guerra Mundi$\mathrm{al}^{1}$. Mantendo-se essa dinâmica, cerca de $50 \%$ dos objetos que estaremos usando nos próximos 10 anos ainda não foram inventa$\operatorname{dos}^{2}$.

Os objetos da propriedade intelectual são as criações da mente humana, a inteligência do homem. A propriedade intelectual pode ser dividida em dois ramos: a Propriedade Industrial, que abrange dentre outras, a patente e a marca, e o Direito de Autor. Dentre alguns tipos de proteção previstos e citados por Silva e Carvalho, de acordo com a natureza do objeto criado, podemos apontar ${ }^{3}$ :

Patente - Proteção legal, temporária, concedida pelo Estado ao inventor ou ao seu titular, dando a este o direito de impedir terceiros de usar, produzir ou realizar qualquer atividade comercial com o bem protegido, sem o seu consentimento. Em contrapartida, o inventor deve descrever o conteúdo técnico abrangido pela invenção para conhecimento do público. Há dois tipos de patentes: as de invenção e as de modelo de utilidade. Patente de Invenção - proteção temporária concedida a um bem tecnológico (produto ou processo) que atenda aos requisitos de novidade, atividade inventiva, isto é, quando apresenta uma transformação qualitativa do estado da técnica, e aplicação industrial. Patente de Modelo de Utilidade - proteção temporária concedida ao objeto de uso prático, ou parte deste, suscetível de aplicação industrial, que apresenta nova forma ou disposição, envolvendo ato inventivo, cujo resultado seja uma melhoria funcional no seu uso ou em sua fabricação. Cita-se como exemplo de patente de invenção a que protegeu os primeiros aparelhos telefônicos o que, inicialmente, resolveu o problema da comunicação pela aplicação da ação eletromag-

*e-mail: luciana@inpi.gov.br nética. A patente de modelo de utilidade por sua vez, seria relativa a alguma modificação na forma ou na estrutura desse aparelho telefônico, por ex., a dos aparelhos em que o transmissor e o receptor foram integrados em uma só peça.

Desenho Industrial - é a proteção legal, por um prazo determinado, na forma de registro, concedida à forma plástica ornamental de um objeto ou conjunto ornamental de linhas e cores que possa ser aplicada a um produto, que proporcione resultado visual novo e original na sua configuração externa e que possa servir de tipo de fabricação industrial. Cita-se como exemplo os desenhos de poltronas.

Marca - é o registro legal para proteger os sinais distintivos visualmente perceptíveis que confere ao seu titular o uso exclusivo, em seu ramo de atividade, permitindo distinguir o produto ou serviço de outro idêntico ou afim, perante os consumidores do bem comercializado. De acordo com sua natureza as marcas podem ser de produto ou serviço, de certificação e coletiva. Além disso, elas poderão ser reconhecidas como de Alto Renome e Notoriamente Conhecida, caso atendam a determinados requisitos. Cita-se como exemplo de marca notoriamente conhecida a Land Rover de veículos, e como exemplo de marca de alto renome a da Coca-Cola.

Indicação Geográfica - constitui indicação geográfica a indicação de procedência ou a denominação de origem. A denominação de origem é o nome geográfico de país, cidade, região ou localidade de seu território que designe produto ou serviço cujas qualidades ou características se devem exclusiva ou essencialmente ao meio geográfico, incluindo fatores naturais e humanos. Considerase indicação de procedência o nome geográfico de país, cidade, região ou localidade de seu território que se tenha tornado conhecido como centro de extração, produção ou fabricação de determinado produto ou de prestação de serviço. Cita-se como exemplo o uso de "champagne" exclusivamente para espumantes fabricados na região de Champagne, na França.

Segredo de Negócio - também denominado segredo de fábrica, é o conjunto de conhecimentos técnicos e informações estratégicas, referentes a um produto, processo e método de produção ou de negócio que leve à obtenção de algum benefício para seu usuário e que não seja divulgado. Cita-se como exemplo de segredo de negócio, o relativo à formulação do refrigerante Coca-Cola, que não é protegido como patente. 
Direito Autoral - é o direito exclusivo conferido pelo Estado ao criador de obras literárias ou artísticas originais, como livros, artigos, desenhos fotografias, composições musicais, gravações e filmes, e abrange os direitos conexos (direitos de intérpretes, executantes, produtores fotográficos e radiodifusão).

Programa de Computador - é o registro legal, baseado no direito de autor, para a expressão de um conjunto de instruções, em linguagem natural ou codificada. Pode ser protegido, quer seja isolado, quer esteja incorporado ao "hardware", como "software" integrado. O meio físico em que se encontra o programa não afeta sua proteção.

Nome de Domínio - é o registro de nomes e palavras que as empresas designam para seus endereços registrados como "sites" na Web.

Cultivar - é o certificado concedido ao melhorista — pesquisador, pessoa física ou jurídica, que obtém o cultivar —, que é definido como a variedade de qualquer gênero ou espécie vegetal superior que seja claramente distinguível de outros cultivares conhecidos por margem mínima de descritores, por sua denominação própria, que seja homogênea e estável quanto aos descritores, por meio de gerações sucessivas e seja de espécie passível de uso pelo complexo agroflorestal, descrita em publicação especializada disponível e acessível ao bem público, bem como a linguagem componente de híbridos.

Uma invenção é o resultado da concepção de uma nova idéia ou de novos conhecimentos sobre produtos e processos. A invenção não é necessariamente incorporada ao processo produtivo. Sua comercialização depende da relação entre o custo de produção, os investimentos anteriores a serem substituídos e o mercado a ser atendido.

Uma inovação resulta da incorporação de novos conhecimentos à atividade produtiva. Pode ser compreendida como uma invenção que se inseriu no processo produtivo ${ }^{4}$.

A Lei no 9.279/96, publicada em 14 de maio de 1996, também chamada de Lei da Propriedade Industrial ${ }^{5}$, é a que regula direitos e obrigações relativos à Propriedade Industrial no que se refere à concessão de patentes de invenção e de modelo de utilidade, à concessão de registro de desenho industrial, à concessão de registro de marca e indicação geográfica, e a transferência de tecnologia. Até a Lei $\mathrm{n}^{\circ}$ 9.279/96 entrar em vigor, o Brasil não concedia proteção via patente para as áreas de produtos farmacêuticos e alimentos. A partir de 1996, com esta Lei, os fármacos passaram a ser patenteados.

\section{INFORMAÇÃO DE PATENTES COMO INSUMO À ATIVIDADE DE PESQUISA E DESENVOLVIMENTO}

Uma das formas de se medir o desenvolvimento de um país está diretamente relacionada ao número de patentes concedidas a seus nacionais em outros países, especialmente os desenvolvidos. Em artigo recente, Wollmann Jr. afirma que "as potências destacam-se pela produção de tecnologia. E uma boa medida da evolução das nações, nessa área, está no número de patentes concedidas internacionalmente". Segundo ele, o Escritório Americano de Propriedade Intelectual (na sigla em inglês, USPTO), concedeu de 1976 a 2005 "aproximadamente 1.226.000 patentes a empresas dos EUA; 556.000 do Japão; 183.000 da Alemanha; 74.000 da França; 54.000 da Inglaterra; 39.000 do Canadá e 28.000 da Itália (...). O Brasil apresenta, modestamente, 975 patentes" 6 .

Um documento de patentes possui informação bibliográfica e técnica. A bibliográfica é apresentada na primeira página do documento e inclui datas, nome e endereço do inventor, do titular da patente e de seu representante legal, assim como identificação do país de procedência do documento e título da invenção. Já a infor- mação técnica compreende uma descrição do estado da arte, uma descrição detalhada da invenção, que permita a um técnico no assunto realizá-la, destacando as diferenças existentes entre a tecnologia anterior e o avanço trazido pela mesma, um ou mais desenhos (quando necessário) e as reivindicações, que definem o escopo da invenção e o que será protegido.

O Artigo 40 da Lei de Propriedade Intelectual (Lei $n^{\circ}$ 9.279) estabelece que "a patente de invenção vigorará pelo prazo de 20 (vinte) anos e a de modelo de utilidade pelo prazo de 15 (quinze) anos contados da data de depósito".

Em comparação com outras fontes de informação tecnológica, a documentação de patentes apresenta vantagens consideráveis, dentre as quais: divulgar informação mais rapidamente do que outras fontes porque na maioria dos países os documentos são publicados antes de sua concessão e, assim, a tecnologia mais recente chega ao conhecimento do público mais rapidamente; possuir uma estrutura uniforme relativa ao "layout" do documento e aos dados bibliográficos, que são identificados através de códigos utilizados por todos os países, o que padroniza e facilita o entendimento da informação qualquer que seja o idioma do documento; abranger todos os campos tecnológicos, indexados de forma coerente e integral (mais de 69.000 itens tecnológicos) pela Classificação Internacional de Patentes (IPC), o que permite uma recuperação fácil da tecnologia desejada, bem como fornecer uma base para determinação de dados estatísticos de certos parâmetros tecnológicos (WIPO, 2000); como a CIP é revista a cada 5 anos por um Comitê de Peritos da Organização Mundial de Propriedade Intelectual e, atualmente, é utilizada por mais de 100 países e entidades internacionais, inclusive o Brasil, existem aproximadamente 27,5 milhões de documentos de patentes que receberam uma classificação e têm a tecnologia indexada de forma contemporânea e integralmente disseminada (WIPO, 1999); conter informação que, na maioria dos casos, não será divulgada de outra maneira. Um estudo de Alfred Marmor (1979), publicado na revista World Patent Information, revela que $71 \%$ da tecnologia contida na documentação de patentes são descritas somente por este veículo, sendo que apenas $16 \%$ são divulgadas integralmente e $13 \%$ de forma parcial por outros meios (periódicos, simpósios, jornais e demonstrações) e, o documento de patente contém, ainda, informações sobre quais países e corporações são ativos no desenvolvimento de novas tecnologias.

Para acompanhar a velocidade de desenvolvimento de novas tecnologias, os pesquisadores precisam assumir uma postura dinâmica em relação à busca de informações pois o volume aproximado de novos pedidos de patentes é de 600 mil por ano, sendo o Japão o país onde há maior número de pedidos de patentes: cerca de 300 mil pedidos por ano ${ }^{7}$.

Segundo a Organização de Patentes da Áustria, poderiam ser economizados cerca de $30 \%$ dos custos de pesquisa e desenvolvimento despendidos na Alemanha caso fossem utilizadas informações técnicas disponíveis em bancos de patentes. Segundo estimativa da Organização Britânica de Patentes, cerca de US\$ 30 bilhões são anualmente desperdiçados na Comunidade Européia devido a invenções duplicadas ${ }^{7}$.

Nos documentos de patentes está a informação mais recente em relação ao estado da técnica de diversas áreas do desenvolvimento humano. A patente é não só uma proteção legal, um bem econômico, mas uma fonte de informação tecnológica que deve ser utilizada para solucionar problemas técnicos e na realização de pesquisas. A pesquisa em bancos de dados de patentes evita que esforços sejam colocados no desenvolvimento de tecnologias já existentes. Além disso, o uso de informações de patentes permite identificar tecnologias emergentes ou alternativas; fornece embasamento para aplicações comerciais, indicando, por ex., me- 
lhores alternativas para compra de tecnologia; permite a verificação da disponibilidade da tecnologia no Brasil, evitando litígios e, permite também o monitoramento de tecnologias concorrentes.

No Brasil, o debate em torno da importância das atividades de pesquisa científica e tecnológica tem se concentrado principalmente no ambiente acadêmico. Grande parte da atividade de pesquisa e desenvolvimento do país ocorre em instituições governamentais, com participação ainda pequena por parte do setor produtivo. No relatório da ONU sobre desenvolvimento, baseado no Índice de Avanço Tecnológico, o Brasil ficou em $43^{\circ}$ lugar, ao lado de Bolívia e Paraguai, e atrás de Argentina, Chile e México ${ }^{8}$. O Projeto de Digitalização Acelerada da Federação das Indústrias do Rio de Janeiro concluiu que “(...) No Brasil apenas $21 \%$ dos produtos exportados agregam tecnologia; na Malásia, esse percentual eleva-se a 57\%; no México, a 50\%"9.

\section{ESTRUTURA DO DOCUMENTO DE PATENTE}

Fazem parte da estrutura do documento de patente a Folha de Rosto, o Relatório Descritivo, as Reivindicações, os Desenhos (e a descrição deles) e o resumo. A Folha de Rosto contém os dados bibliográficos da patente, o resumo e pode conter figura.

As informações da Folha de Rosto são identificadas por um código numérico. Esses códigos são conhecidos como códigos INID ("International Agreed Numbers for the Identification of Data"). A Organização Mundial da Propriedade Intelectual ("World Intellectual Property Organization, WIPO”) é responsável por definir padrões na área de PI, sendo que o aplicado aos documentos de patentes é definido como ST. $9^{10}$.

No Relatório Descritivo é apresentada uma descrição detalhada dos procedimentos tecnológicos associados à invenção. $\mathrm{O}$ relatório deve conter o título da invenção, o estado da técnica, a definição da invenção e seu campo de aplicação, exemplos práticos e modo de operação.

Quando pertinente ao assunto da invenção, o documento de patente apresenta desenhos e a descrição detalhada deles.

As Reivindicações indicam o âmbito de abrangência da matéria reivindicada e, conseqüentemente, delimitam a proteção assegurada por ela. Não há restrição quanto ao número de reivindicações do documento de patente.

\section{Códigos INID}

Os códigos INID identificam todas as informações que constam da folha de rosto do documento de patente. Seguem alguns exemplos de códigos INID ${ }^{11}$.

Indicação de números

(11) Número do documento

(21) Número designado ao documento quando de seu depósito

(31) Número designado ao primeiro depósito (prioridade do documento).

\section{Indicação de datas}

(22) Data de depósito da solicitação

(32) Data de depósito da primeira solicitação (data de prioridade)

(41) a (47) Referem-se a documentos de patentes publicados [examinados ou não, mas que ainda não têm a decisão final (concessão ou não da patente)]

(45) a (47) Referem-se à data de concessão da patente, geralmente é usado o número (45).

\section{Identificação propriamente dita}

(19) Nome do país ou organização regional ou internacional que publicou o documento de patente

(33) País ou países do primeiro documento (prioridade)

(70) a (76) Identificação de partes relacionadas com o documento:
(71) Nome do depositante

(72) Nome do inventor, se conhecido

(73) Nome de quem detém os direitos sobre a patente

(74) Nome do procurador ou agente

(75) Nome do inventor, quando também for o depositante

Indicação técnica

(12) Tipo de documento (Patente de invenção, Modelo de utilidade, etc.)

(51) Classificação Internacional de Patente

(52) Classificação Nacional ou doméstica de patente

(54) Título da Invenção

(56) Lista de documentos anteriores citados pelo depositante (pode auxiliar no exame) ou encontrados pelo examinador de patentes durante a busca para exame

(57) Resumo do conteúdo do documento

\section{CLASSIFICAÇÃO INTERNACIONAL DE PATENTES (CIP)}

A Classificação Internacional de Patentes surgiu a partir da necessidade de criação de uma ferramenta de busca e recuperação de documentos de patente. É um instrumento que possibilita a organização dos documentos de patente, usado com a finalidade de facilitar o acesso às informações tecnológicas e legais contidas nos mesmos.

As primeiras discussões para elaboração da CIP tiveram início em torno de 1920, mas só na Convenção Européia para a Classificação Internacional de Patentes, em 1954, foram estabelecidos alguns critérios. A primeira edição da CIP data de 1969 e seu texto foi publicado de acordo com a Convenção Européia de 1954. Atualmente a CIP está na sétima edição, datada de 1999. A classificação é periodicamente revisada a partir de reuniões de peritos dos Países Membros da Organização Mundial da Propriedade Intelectual, sendo publicada em CD-ROM e podendo ser acessada nos sites do INPI e da OMPI. Até 1999 era reeditada a cada 5 anos, a sétima edição contudo, teve sua utilização estendida até 31/12/2005. A oitava edição entrará em vigor a partir de 1/1/2006 e conterá modificações não apenas em relação ao desenvolvimento tecnológico, que gera a criação de novos grupos e sub grupos, mas também com relação ao seu formato que passará entre outras modificações, a ser composto de cinco volumes e não mais de dez como até agora.

Atualmente a estrutura hierárquica da CIP engloba 8 seções, 21 subseções, 120 classes, 628 subclasses e 69000 grupos.

\section{Seções da CIP}

As oito seções da CIP são identificadas pelas letras A a $\mathrm{H}$ e abrangem todas as áreas do desenvolvimento tecnológico humano. Estas seções são as seguintes:

A -Necessidades Humanas

B - Operações de Processamento; Transporte

C-Química e Metalurgia

D - Têxteis e Papel

E - Construções Fixas

F - Engenharia Mecânica, Iluminação; Aquecimento; Armas; Explosão

$\mathrm{G}$-Física

$\mathrm{H}$-Eletricidade

A título de exemplo, na Seção $\mathrm{A}$, relativa às necessidades humanas, encontram-se 4 subseções:

A01 - Agricultura

A02 - Produtos alimentícios e tabaco

A03 - Artigos para uso pessoal e doméstico

A04 - Saúde e recreação 


\section{Exemplo}

A título de exemplo, será analisada a classificação internacional do documento de patente PI9708655-0, intitulado DERIVADOS DE ISATINA COMO INIBIDORES DE ACETILCOLINESTERASE E ANALGÉSICOS, que foi depositado no INPI em 07/03/1997. Constam do documento duas classificações: C07D 401/12 e A61K 31/44. Será analisada a classificação C07D 401/12.

Tabela 1. Análise do significado da classificação internacional de patente C07D 401/12

\begin{tabular}{|c|c|c|}
\hline Seção & $\mathrm{C}$ & Química e Metalurgia \\
\hline Subseção & $\mathrm{C} 07$ & Química Orgânica \\
\hline Classe & C07D & Compostos heterocíclicos \\
\hline Subclasse & C07D 401 & $\begin{array}{l}\text { Compostos heterocíclicos contendo } \\
\text { dois ou mais heteroanéis, tendo } \\
\text { átomos de nitrogênio como os } \\
\text { únicos heteroátomos do anel, pelo } \\
\text { menos um dos anéis sendo de um } \\
\text { de seis membros, com apenas um } \\
\text { átomo de nitrogênio }\end{array}$ \\
\hline Grupo & C07D 401/12 & $\begin{array}{l}\text { Compostos heterocíclicos ligados } \\
\text { por uma cadeia contendo heteroáto- } \\
\text { mos como elos da cadeia }\end{array}$ \\
\hline
\end{tabular}

\section{FORMAS DE PUBLICAÇÃO DA CLASSIFICAÇÃO INTERNACIONAL DE PATENTES}

A CIP é publicada em 10 volumes: os 8 primeiros são relativos às diversas seções; o $9^{\circ}$ e o $10^{\circ}$ são guias. A CIP é publicada também em CD Rom, intitulado IPC: CLASS, e pode ser acessada no endereço eletrônico do INPI ${ }^{12}$.

\section{Bancos de dados}

Cada banco de dados possui características e particularidades próprias. Existem diversos bancos de dados que permitem o acesso a várias bases de dados, que possuem enorme gama de informações. As bases de dados que podem ser acessadas variam de um banco de dados para outro.

\section{Bancos de dados de acesso gratuito}

A documentação de patentes é disponibilizada no Brasil pelo Instituto Nacional da Propriedade Industrial (INPI), em forma impressa, em microfilmes e em CD Rom. Pode também ser acessada por meios eletrônicos. No endereço eletrônico do INPI encontra-se disponível um banco de dados com todos os pedidos de patentes brasileiras publicados a partir de agosto de 1992. Constam da base aproximadamente 50 mil registros. Uma informação preliminar pode ser, assim, obtida de forma gratuita via internet.

Em 1994, em convênio com a Fundação André Tosello, o INPI foi o primeiro Escritório de Propriedade Industrial a disponibilizar, via internet e gratuitamente, as informações bibliográficas contendo os resumos de sua base de dados de patentes. Esta iniciativa foi precursora e demonstra a preocupação do INPI quanto à disseminação das informações sobre patentes. Os documentos completos de patentes podem ser solicitados ao INPI ${ }^{13}$.

O INPI permite acesso às suas instalações na modalidade de busca individual, em que o interessado faz a busca contando com a orientação de técnicos, mediante o pagamento de uma taxa ( $R$ \$ 20,00 para ter acesso à documentação em papel e em meios eletrô- nicos por cinco dias). Existem, ainda, duas outras modalidades de busca: uma é a busca isolada, feita por técnicos do INPI por solicitação do interessado, que receberá um relatório com levantamento completo do estado da técnica e com os documentos relativos à busca. O custo da busca isolada depende do volume de homens/h que ela demanda, estando seu custo médio em torno de $\mathrm{R} \$ 400,00$. A outra modalidade é a busca on-line, também realizada por técnicos do CEDIN, em bases de dados comerciais, não podendo seu custo ser determinado antes do término da pesquisa, mas sempre é dada uma estimativa de valor antes de iniciá-la. O custo médio está em torno de US\$150,00, devido ao pagamento das mesmas ser feito a empresas no exterior.

Através da própria página do INPI na internet ${ }^{14}$ é possível acessar bancos de dados gratuitos de diversos escritórios de patente do mundo:

Pedidos PCT: http://www.wipo.int/ipdl/en/index.jsp

Produto do projeto WIPO IPDL (Biblioteca Digital de Propriedade Intelectual da OMPI), esta base contém os documentos completos dos pedidos de patente depositados via PCT.

Patentes dos EUA - USPTO: http://patft.uspto.gov/netahtml/ search-adv.htm

Site do USPTO, Organização Americana de Marcas e Patentes. A base contém todos os documentos de patente americanas desde o número um. As buscas em texto completo só podem ser realizadas nos documentos publicados a partir de janeiro de 1976, aqueles anteriores a esta data só podem ser pesquisados por número ou pela classificação americana. Existem ainda as bases de busca por número de documento e por pedido publicado.

Base de Patentes do Escritório Europeu de Patentes:

h t t p ://e p.es pacenet.com/search 97 c g i / s97_cgi.exe?Action=FormGen\&Template $=$ ep/en/advanced.hts

Site mantido pelo Escritório Europeu de Patentes (EPO), permite a pesquisa nos dados bibliográficos de patentes de diversos países, e também no texto e nas reivindicações. Algumas das patentes selecionadas podem ser vistas na sua forma integral, inclusive desenhos, com possibilidade de se obter suas patentes correspondentes.

Patentes do Japão: http://www19.ipdl.ncipi.go.jp/PA1/cgi-bin/ PA1INIT?1113315120338

Site mantido pelo Escritório Japonês de Patentes, permite a pesquisa nos dados bibliográficos dos pedidos de patentes no Japão, com a possibilidade de se obter cópia dos documentos originais japoneses.

Todos esses bancos de dados são extremamente completos e contêm as coleções de patentes dos mais importantes países, a maior desvantagem deles em relação aos bancos de dados comerciais está relacionada às limitações quanto aos procedimentos de busca. Para uma busca bem-sucedida, é fundamental a escolha acertada de palavras-chave.

Bancos de dados comerciais, com acesso mediante pagamento

Os bancos de dados mais conhecidos são o DIALOG e o STN ("The Scientific \& Technological Information Network"), que têm grande especialização na área química ${ }^{15}$. $\mathrm{Na}$ área químico-farmacêutica, existem muitas bases de dados, sendo que a CA SEARCH, CHEMNAME, MEDLINE, FINE CHEMICAL e DRUG INFORMATION FULLTEX são as mais importantes.

A base de dados INPADOC ("International Patent Documentation Center") é especializada em família de patentes (Documentos correspondentes a uma determinada patente em outros países), tem um custo aproximado de US\$ 15,00 por documento de patente pesquisado. A base WPI ("World Patent Index") tem um custo de US\$ 330,00 por h de conexão mais o custo de 
cada documento solicitado, variando este custo entre US\$2,00 à US\$ 10,00 conforme o formato solicitado (Com mais ou menos informações). Seus valores são elevados devido ao fato desta base reescrever os resumos de todos os documentos de patente de seu acervo, oriundos de cerca de 60 países a partir de 1960 .

\section{CONCLUSÃO}

Como uma grande parte da informação tecnológica disponibilizada anualmente no mundo é divulgada somente sob a forma de documentos de patente, a pesquisa em bancos de dados de patente é indispensável para o desenvolvimento científico de um país. No Brasil, como a pesquisa científica está concentrada principalmente em centros acadêmicos e centros de pesquisa governamentais, é extremamente positiva não apenas a mais ampla divulgação das informações de patentes nesses âmbitos, mas também o estímulo à pesquisa bibliográfica em bancos de patentes por alunos de cursos tecnológicos de graduação e pós-graduação.

\section{REFERÊNCIAS}

1. Prince, D. S.; Little Science, Big Science, Columbia University Press: New York, 1963.

2. De Brachard, J. P.; A margem do futuro, Nova Fronteira: Rio de Janeiro, 1991.
3. Silva, L. F.; Carvalho, M. B.; Aspectos Gerais da Propriedade Intelectual nas Instituições de Ensino e Pesquisa, Cadernos REPICT (Rede de Tecnologia do Rio de Janeiro), Ed. E-papers: Rio de Janeiro, 2004, vol.1.

4. Brasil, Lei $N^{\circ} 10.973$, de 2 de dezembro de 2004. Dispõe sobre Incentivos à Inovação e à Pesquisa Científica e Tecnológica no Ambiente Produtivo.

5. Brasil, Lei $\mathrm{N}^{\circ} 9.279$, de 14 de maio de 1996. Regula Direitos e Obrigações relativos à Propriedade Industrial.

6. Wollmann Jr., D.; Jornal O Globo; O Brasil só tem 975 patentes; p. 7, Opinião, 24 de janeiro de 2005.

7. Oliveira, L. G.; Suster, R.; Material apresentado no Curso "Busca de Informação Tecnológica em Bases de Dados de Patentes”. Realização da Rede de Tecnologia e INPI, Rio de Janeiro, 10 a 12 de maio de 2004.

8. Santos, W. G.; Jornal do Brasil; A razão dos miseráveis, p. 3 (Brasil), de 01 de julho de 2001.

9. Racy, S.; Jornal O Estado de São Paulo, Coluna Direto da Fonte, p. B-2, de 27 de novembro de 2000.

10. http://www.bl.uk/collections/patents/inid.html, acessada em Março 2005.

11. World Intellectual Property Organization (WIPO); Handbook on Industrial Property Information and Documentation. Ref: Standards - ST.9, page 3.9.0-3.9.10, February 2004.

12. http://www.inpi.gov.br/patentes/pdf/GUIA-7\%AA\%20Edi\%E7\%E3o.pdf, acessada em Março 2005.

13. Fornecimento de cópias de documento de patente: as solicitações podem ser feitas ao CEDIN ou as representações do INPI nos estados, pessoalmente, por fax, carta, ou e-mail: copdocpat@inpi.gov.br.

14. Na página principal do INPI, acessar "Sites da Propriedade Intelectual" e então "Sites de pesquisas em bases de patentes estrangeiras".

15. http://www.stn-international.de, acessada em Março 2005. 